\title{
Ascending aortic diameter influence on the left ventricle function in hypertensives: A study using GE-P 100 doppler echocardiograph
}

\author{
Vijaykumar Narayana', H. L. Niranjan Murthy², Rajeev Sharma ${ }^{3}$ \\ ${ }^{1}$ Faculty of Medicine (Department of physiology), International Medical School, Management \& Science University, Shah Alam, Seksyen 13, \\ 40100, Malaysia, ${ }^{2}$ Assistant Professor, Physiology, ESIC-MC \& PGIMSR, Bangalore, India, ${ }^{3}$ Professor \& HOD, Physiology, Sapthagiri Institute \\ of Medical Sciences \& Research center, Bangalore, India
}

\section{A B S TR A C T}

Background: When the heart faces a hemodynamic burden, increasing mass assumes a key role in the compensation for hemodynamic overload. A strong confounding factor in this relation is the altered ascending aortic haemodynamics in hypertensives due to altered ascending aortic diameter at annulus. Objectives: Ascending aortic diameter has an effect on the after load which may affect the left ventricular function. We studied to investigate the influence of the ascending aortic diameter on the left ventricular function in hypertensives. Improving the haemodynamics in such conditions may reduce mortality rates and result in better quality of life. Material and methods: We conducted a case control study involving hypertensive patients $(n=25)$ and normotensive subjects $(n=25)$ of same age group acting as controls. Ascending aortic diameter was measured at annulus and using M mode echocardiography we measured the thickness of the interventricular septum \& posterior wall. Diameter of the ventricle during systole and diastole were obtained. All measurements were taken according to the American Society of Echocardiography recommendation. Results: The measured parameter ejection time $(r=0.545, n=25, p=0.005)$ and left ventricular internal diameter during diastole $(r=0.348, n=25, p=0.02)$ showed a very high significant positive correlation with the ascending aortic diameter. Conclusion: We would conclude to say that the reduced ascending aortic diameter has a significant effect on left ventricular wall and left ventricle function in hypertensives. The Doppler evaluation of ascending aortic diameter in hypertensives may help in achieving a reduction in morbidity and mortality due to hypertension induced cardiovascular disorders.

Key words: Ascending Aortic Diameter, Left Ventricle Internal Diameter, Essential Hypertension, Ejection Time

\section{INTRODUCTION}

Hypertension is a hemodynamic derangement. It is the primary and most important manifesting symptom of hypertensive vascular disease. Cardiac compensation for the excessive workload imposed by increased systemic pressure is at first sustained by left ventricular hypertrophy. Left ventricular hypertrophy is a powerful independent predictor of cardiovascular morbidity and mortality. According to LaPlace's Law, the load on any region of the myocardium is given as follows: (pressure $\times$ radius)/ ( $2 \times$ wall thickness). Systolic stress (afterload) is a major determinant of ejection performance, there was a strong correlation reported between the wall stress and the ventricular performance. ${ }^{1}$

The concept for defining afterload is in terms of the impedance to blood flow entering the aorta, known as arterial input impedance which in turn is determined by the arterial pressure, elasticity, vessel dimension, and blood

Address for Correspondence:

Vijaykumar Narayana, Faculty of Medicine (Department of Physiology), International Medical School, Management \& Science University,

Shah Alam, Seksyen 13, 40100, Malaysia.

E-mail: drvkn2612@gmail.com; Moblie: +601126327749

(c) Copyright AJMS 
viscosity. One such cause exposing the ascending aorta to excessive mechanical trauma and altering the physiology of aortic blood flow is systemic hypertension. Ascending aortic diameter is altered in hypertensives due to the shear stress at the annulus. The implication is that mechanical input is transduced into a biochemical event that modifies gene transcription in the nucleus. An excellent candidate for such a transducer is the focal adhesion complex, whereby integrins connect the internal cytoskeleton of the cell to the extracellular matrix. ${ }^{2}$

The change in the ascending aortic diameter due to hypertension may be one of the strong confounding factors for the left ventricular hypertrophy. Systemic hypertension, a common disorder with potentially serious complications exerts ill effects through structural and functional modifications of arterial wall. ${ }^{1,2}$ A recent study reported significant influence of afterload on radial \& longitudinal myocardial function in animals. ${ }^{3}$

Hypertension and diabetes were reported to have independent influence on the left ventricle function, independent of the effect of overweight/obesity and other covariates. ${ }^{4}$

Previous studies using different techniques have shown that with increased arterial blood pressure, diameter of ascending aorta may be altered. This may be due to an increase in peripheral resistance or by changes in aortic wall structure. ${ }^{5}$ Also a study designed to analyze the age and gender effect on left ventricle function concluded that functional age related changes in left ventricle function were more prominent in the long axis, while differences between genders were more pronounced in short axis and in volume measurements. ${ }^{6}$ Aortic stenotic was said to trigger a hypertrophic response, leading to change in the left ventricular wall thickness and mass but the degree of hypertrophy did not closely correlate with the severity of valve narrowing. ${ }^{7}$ The reproducibility of doppler recordings of ascending aortic diameter with acceptable intraobserver, interoobserver and day-to-day variability was demonstrated. ${ }^{8}$ With the validation of a third generation doppler velocity system for studies of detailed aortic haemodynamics, ${ }^{9}$ it has become easier to evaluate the ascending aortic diameter. Doppler aortic diameter measurements can be made with nonimaging technique with acceptable intraobserver, interobserver and day-to-day variability, but recording and interpretation done by same observer would be expected to reflect a true change. ${ }^{11}$ Echocardiographic measurement of ascending aorta was not a problem as the diameter estimated by Doppler was almost similar to angiographic aortic diameter measurement. ${ }^{12}$

The interest in ascending aortic diameter relation with the left ventricular function is clear, on one hand it helps in maintaining normohaemodynamic state and producing adequate perfusion of all organs and in another note a significant number of cardiovascular disorders related to disordered left ventricle can be reduced. Improving it in such conditions will reduce mortality rates and result in better quality of life, Since we could not find such a study in literature, this prompted us to investigate and establish the relationship between the ascending aortic diameter and left ventricular function in normal individuals and compare the same with hypertensives.

\section{MATERIALS AND METHODS}

\section{Source of data}

This is a case control study and hence 25 cases of hypertensive patients attending cardiology department at M.S.Ramaiah Medical Teaching Hospital were studied and further compared with 25 normotensive subjects of same age group acting as controls.

\section{Method of collection of data}

Twenty-five essential hypertensive patients attending cardiology department at M.S.Ramaiah Medical Teaching Hospital who satisfy the inclusion criteria were subjects for this study. This study was conducted from Aug 2002 to Dec 2003.

JNC VI, 1992 guidelines for hypertension was followed. The inclusion and exclusion criteria were designed to meet our objective. ${ }^{1,2,4,6,7}$

\section{Inclusion criteria}

1. Patients between 30 to 50 years of age, of both sexes

2. On drug therapy whether controlled or uncontrolled

3. Of more than three months duration

4. With or without left ventricle hypertrophy

\section{Exclusion criteria}

1. Patients with aortic valve disease [Ruled out by Echocardiography (ECHO)]

2. Patients with any other cardiac illness (Ruled out by Electrocardiogram and ECHO)

3. Patients with diabetes (Ruled out by Glucometer Random Blood Sugar)

\section{System design}

The GE - P 100 Doppler echocardiography machine was used for the study. The transducer for ascending aortic flow recordings was of low frequency. The sector scanner used in the present study was equipped with a $3 \mathrm{MHz}$ transducer with a half power bean width of approximately $3 \mathrm{~mm}$ transducer. The frozen images were recorded on a glossy black-on-white electrostatic paper at a speed of $50 \mathrm{~mm} / \mathrm{sec}$. 


\section{Protocol design}

Informed consent was obtained from the volunteers and the hypertensive patients visiting cardiology department. Ethical clearance was obtained from ethical committee of $\mathrm{M}$ S Ramaiah Medical Teaching Hospital. Three measurements were taken to minimise the error in measurement and the average of the same were considered. ${ }^{11}$ The aortic annulus diameter was measured as the distance between the insertion of two adjacent leaflets on the parasternal long axis view or on the midesophageal long-axis view of the ascending aorta and aortic valve at end-systole. Measurements were taken according to the American Society of Echocardiography recommendations. ${ }^{13} \mathrm{On}$ M-Mode echocardiography the following structural parameters were assessed in long axis view, ${ }^{6}$

I. Thickness of posterior wall and the interventricular septum.

II. Left ventricular diameter during systole and diastole.

III. All measurements of the septum and the posterior wall were performed at the end of diastole according to recommendation of American Society of Echocardiography.

IV. Direct measurement of ventricular diameter was obtained in echocardiography. In this geometrical concept stroke volume and cardiac output were calculated,

a. The Stroke Volume (SV) was calculated by the formula ${ }^{8} \mathrm{SV}=\left(\mathrm{LVID}_{\mathrm{d}}\right)^{3}-\left(\mathrm{LVID}_{\mathrm{s}}\right)^{3}$,

LVID $_{d}$ - Left ventricular internal diameter at diastole, LVIDs - Left ventricular internal diameter at systole)

b. Cardiac output $(\mathrm{CO})=$ Stoke volume $\mathrm{x}$ heart rate $\mathrm{V}$. Left ventricular Index of Preload=EDV / BSA14

(EDV=End diastolic volume, BSA=Body surface area)

\section{RESULTS AND STATISTICAL ANALYSIS}

For statistical analysis, the parameters were recorded with SPSS for windows (11) software. Demographic and pressure parameters as well as echocardiography analysis were presented as mean \pm standard error, between the normotensive and hypertensive groups.

The Pearson correlation was used to know the interrelationship of the parameters with the ascending aortic diameter. The tests were considered significant if a value of $\mathrm{P}<0.05$ was considered statistically significant, ${ }^{*}$ $\mathrm{P}<0.02$ was considered statistically highly significant $* *$ and $\mathrm{P}<0.01$ was considered statistically very highly significant. *** (The null - hypothesis was applied).

Table 1 explains the general parameters of the normotensive and hypertensives included in the study. The normotensive and hypertensives included in the study were age, height and weight matched. There were no significant difference with respect to age, height, weight, body surface area and packed cell volume between normotensive and hypertensives. But the results showed a very highly significant difference in systolic and diastolic blood pressure $(\mathrm{P}<0.01)$.

Table 2 explains the Doppler M- mode Echocardiography parameter comparison. There was statistically very highly significant increase in the ejection time $(339 \pm 42.2, \mathrm{p}=0)$, decrease in the left ventricular internal diameter during systole $(2.56 \pm .409, \mathrm{p}=0)$ and increase in the left ventricular internal diameter during diastole $(4.46 \pm .56, \mathrm{p}=0)$. The preload index $(51 \pm 11, \mathrm{p}=0.02)$ showed a significant decrease in hypertensive.

Table 3 explains the correlation of ascending aortic diameter with various parameters in normotensive and hypertensive. The measured parameter ejection time $(\mathrm{r}=0.545, \mathrm{n}=25, \mathrm{p}=$ $0.005)$ and left ventricular internal diameter during diastole $(\mathrm{r}=0.348, \mathrm{n}=25, \mathrm{p}=0.02$ showed a very high significant positive correlation with the ascending aortic diameter. While the systolic blood pressure $(\mathrm{r}=0.375, \mathrm{n}=25, \mathrm{p}=$ 0.04 ) and left ventricular internal diameter during systole $(\mathrm{r}=0.271, \mathrm{n}=25, \mathrm{p}=0.03)$ showed a statistically significant positive correlation. These results showed that there was a strong positive correlation in hypertensives when compared with the control (normotensive).

\begin{tabular}{|c|c|c|c|c|c|c|}
\hline & \multicolumn{2}{|c|}{ Normotensives } & \multicolumn{2}{|c|}{ Hypertensives } & \multirow{2}{*}{$\begin{array}{c}\text { Test for equality } \\
\text { of means } \\
t\end{array}$} & \multirow{2}{*}{$\begin{array}{c}\text { Significance } \\
\text { P value }\end{array}$} \\
\hline & Mean & SD & Mean & SD & & \\
\hline Age (years) & 41 & 6.455 & 44.2 & 6.677 & 1.723 & 0.091 \\
\hline Height (CMS) & 168 & 2.71 & 169.75 & 2.65 & 1.623 & 0.111 \\
\hline Weight (Kg) & 59.44 & 4 & 60.76 & 6.25 & 0.889 & 0.378 \\
\hline Body surface area (Sq. m) & 1.99 & 0.011 & 1.97 & 0.004 & 1.992 & 0.15 \\
\hline Packed cell volume $(\%)$ & 40.56 & 2.21 & 40.7 & 2.758 & 0.13 & 0.84 \\
\hline Systolic BP & 114.72 & 4.99 & 144 & 11.04 & 12.07 & $0^{* * *}$ \\
\hline Diastolic BP & 79.76 & 2.9 & 94.72 & 4.11 & 14.84 & $0^{* * *}$ \\
\hline
\end{tabular}

Kg - Kilogram, CMS - Centimetres Sq., m - Square meter, \% - Percentage 


\section{DISCUSSION}

The results of our study have helped us to ascertain our hypothesis that ascending aortic diameter has a profound influence on left ventricular function.

The statistically significant increase in ejection time in our study is probably due to the decrease in aortic compliance

\begin{tabular}{|c|c|c|c|c|c|}
\hline & \multicolumn{2}{|c|}{ Normotensives } & \multicolumn{2}{|c|}{ Hypertensives } & \multirow{2}{*}{$\begin{array}{c}\text { Student's } \\
\text { t test } \\
\text { P value }\end{array}$} \\
\hline & Mean & SD & Mean & SD & \\
\hline DIA & 1.73 & 0.1868 & 1.533 & 0.408 & $0.037^{*}$ \\
\hline $\mathrm{ET}$ & 287.9 & 22.31 & 339 & 42.2 & $0^{* * *}$ \\
\hline LVIDS & 3.13 & 0.34 & 2.56 & 0.409 & $0^{* * *}$ \\
\hline LVIDD & 3.86 & 0.486 & 4.46 & 0.56 & $0^{* * *}$ \\
\hline IVSD & 1.02 & 0.128 & 0.934 & 0.302 & 0.159 \\
\hline IVSS & 1.145 & 0.182 & 0.066 & 0.334 & 0.117 \\
\hline Preload index & 58.01 & 5.8 & 51 & 11 & $0.02^{* *}$ \\
\hline Cardiac Index & 2.8 & 0.24 & 3 & 0.74 & 1.16 \\
\hline $\begin{array}{l}\text { VIDD - Left ventricl } \\
\text { nternal diameter du } \\
\text { luring diastole in m } \\
\text { IA - Diameter of as } \\
\text { ninute/square mete }\end{array}$ & $\begin{array}{l}\text { internal dia } \\
\text { ng systole } \\
\text { IVSS - Inte } \\
\text { nding aor }\end{array}$ & $\begin{array}{l}\text { neter duri } \\
\mathrm{cm} \text {, IVSD }\end{array}$ & diastole i & $\begin{array}{l}\mathrm{cm} \text {, LVIDS } \\
\text { le septal }\end{array}$ & $\begin{array}{l}\text { Left ventricle } \\
\text { meter } \\
\text { tole in } \mathrm{mm} \text {, } \\
\text { q. } \mathrm{mt}=\text { litres/ }\end{array}$ \\
\hline
\end{tabular}

\begin{tabular}{|c|c|c|}
\hline & \multicolumn{2}{|c|}{ DIA } \\
\hline & Normotensives & Hypertensives \\
\hline \multicolumn{3}{|l|}{ SBP } \\
\hline Pearson corelation & 0.262 & 0.375 \\
\hline Sig. (2-tailed) & 0.206 & $0.04^{*}$ \\
\hline $\mathrm{N}$ & 25 & 25 \\
\hline \multicolumn{3}{|l|}{ DBP } \\
\hline Pearson corelation & 0.23 & 0.367 \\
\hline Sig. (2-tailed) & 0.268 & 0.071 \\
\hline $\mathrm{N}$ & 25 & 25 \\
\hline \multicolumn{3}{|l|}{ ET } \\
\hline Pearson corelation & 0.435 & 0.545 \\
\hline Sig. (2-tailed) & $0.03^{*}$ & $0.005^{\star * *}$ \\
\hline $\mathrm{N}$ & 25 & 25 \\
\hline \multicolumn{3}{|l|}{ LVIDS } \\
\hline Pearson corelation & 0.271 & 0.271 \\
\hline Sig. (2-tailed) & $0.04^{*}$ & $0.03^{*}$ \\
\hline $\mathrm{N}$ & 25 & 25 \\
\hline \multicolumn{3}{|l|}{ LVIDD } \\
\hline Pearson corelation & 0.106 & 0.348 \\
\hline Sig. (2-tailed) & 0.97925 & $0.02^{\star *}$ \\
\hline $\mathrm{N}$ & 25 & 25 \\
\hline \multicolumn{3}{|l|}{ IVSD } \\
\hline Pearson corelation & 0.132 & 0.209 \\
\hline Sig. (2-tailed) & 0.529 & 0.316 \\
\hline $\mathrm{N}$ & 25 & 25 \\
\hline \multicolumn{3}{|l|}{ IVSS } \\
\hline Pearson corelation & 0.069 & 0.198 \\
\hline Sig. (2-tailed) & 0.744 & 0.342 \\
\hline $\mathrm{N}$ & 25 & 25 \\
\hline
\end{tabular}

Asian Journal of Medical Sciences | Oct-Dec 2014 | Vol 5 | Issue 4 which offers an increased resistance to left ventricular ejection. The magnitude of shear stress in straight vessels can be estimated as being directly proportional to the viscosity of blood and inversely proportional to the third power of the inner radius of vessel. ${ }^{14}$

A decrease in aortic compliance represents an increased resistance to left ventricular ejection and therefore is a component of the after load on the left ventricle. ${ }^{1 \& 2}$ Decrease in the ascending aortic diameter results in elevated afterload on the left ventricle. This can influence LV systolic function by blunting contractile reserve, increasing cardiac energy required to provide blood flow, and raising myocardial oxygen consumption for a given stroke volume. ${ }^{15}$

Elevated afterload can alter the left ventricular geometry resulting in increased wall stress. This increases out relative load (ratio of systolic left ventricular pressure to isovolumetric left ventricular pressure) which leads to incomplete myocardial relaxation and in an upward shift of the entire diastolic pressure-dimension relation. Afterload exceeding $80 \%$ of peak isovolumetric pressure increased diastolic pressures and resulted in an upward shift of the diastolic left ventricular pressure-Internal diameter relation. These levels of afterload induced frank diastolic dysfunction. ${ }^{15}$

An increase in left ventricle wall stress caused by hypertension induced increase in afterload will stimulate myocyte hypertrophy, collagen formation and fibroblasts, and thus remodeling of the myocardium with a disproportionate increase in fibrous tissue. ${ }^{16}$ The statistically very highly significant decrease in the left ventricular internal diameter during systole and increase in the left ventricular internal diameter during diastole ascertains this. These changes will subsequently reduce left ventricular compliance, leading to diastolic dysfunction.

The decrease in the left ventricular internal diameter during systole can influence left ventricular systolic function by blunting contractile reserve, increasing cardiac energy required to provide blood flow, and raising myocardial oxygen consumption for a given stroke volume. This may be a cause for development of myocardial infarction. ${ }^{17}$

\section{CONCLUSION}

We would conclude to say that the hypertension has an effect on ascending aortic diameter and the reduced ascending aortic diameter has a significant effect on left ventricular wall and left ventricle function. This altered haemodynamics may lead to further ill effects by way of reduced coronary blood flow and altered peripheral haemodynamics. 
This Doppler evaluation of ascending aortic diameter can be developed as a clinical tool for assessing the benefit of treatment of hypertension.

\section{LIMITATION}

The duration of hypertension and pharmacological intervention were not taken into consideration.

\section{ACKNWOLEDGMENT}

We thank the M S Ramaiah Medical College and the cardiology department to have permitted and supported this work. We thank the echocardiograph technician, nursing and all the staff of the cardiology department for helping us with the collection of the data.

\section{REFERENCES}

1. Gunther $S$ and Grossman W. Determinants of ventricular function in pressure-overload hypertrophy in man. Circulation 1979; 59:679-688.

2. Borg TK and Burgess ML. Holding it all together: organization and functions of the extracellular matrix of the heart. Heart Failure 1993; 8:230-238.

3. Donal E, Bergerot C, Hélène Thibault, Ernande L, Loufoua J, Augeul L, et al. Influence of afterload on left ventricular radial and longitudinal systolic functions: a two-dimensional strain imaging study. European Journal of Echocardiography 2009; 10 : 914-921.

4. Russo C, Jin Z, Homma S, Rundek T, Elkind MSV, Sacco RL, et al. Effect of diabetes and hypertension on left ventricular diastolic function in a high-risk population without evidence of heart disease. European Journal of Heart Failure 2010; 12: 454-461.

5. Bergel DH. Static elastic properties of the arterial wall. Journal of physiology 1961; 156(3): 445-457.

6. Sveälv BG, Fritzon G and Andersson B. Gender and age related differences in left ventricular function and geometry with focus on the long axis. Eur J Echocardiography 2006; 7 (4): 298-307.
7. Dweck MR, Joshi S, Murigu T, Gulati A, Alpendurada F, Jabbour $A$, et al. Left ventricular remodeling and hypertrophy in patients with aortic stenosis: insights from cardiovascular magnetic resonance. Journal of Cardiovascular Magnetic Resonance 2012; 14:50 doi: 10.1186/1532-429X-14-50.

8. Rumberger JA, Fastenow CF, Laughlin DL and Marcus ML. Validation of third generation Doppler system for studies of detailed aortic flow. AM Journal of heart and circulatory physiology 1984; 247:846-847.

9. Giscold SE and Brubakk AO. Measurement of instantaneous blood flow velocity in the human aorta using pulsed Doppler ultrasound. Cardiovascular research 1982; 16: 26-33.

10. Kim M M, Roman MJ, Cavallini MC, Schwartz JE, Pickering TG and Devereux RB. Effect of hypertension on aortic root size and prevalence in aortic regurgitation. American heart association 1996; 28: 47-52.

11. Izzo JL and Shykoff BE. Arterial stiffness clinical relevance measurement treatment. Rev cardiovascular medicine 2001; 2 (1): $29-40$.

12. Castro CM, Cruzado MC, Miatello RM and Rislerl NR. Proteoglycan production by vascular smooth muacle cells from resistance arteries of hypertrensive rats. Hypertension 1999; 34(2): 893-896.

13. Sahn DJ, DeMaria A, Kisslo $J$ and Weyman A. The Committee on M-Mode standardization of the American Society of Echocardiography. Recommendations regarding quantitation in M-Mode echocardiography: results of a survey of echocardiographic measurements. Circulation 1978; 58: 1072-1083.

14. Levy D, Garrison RJ, Savage DD, Kannel WB and Castelli WP. Prognostic implications of echocardiographically determined left ventricular mass in the Framingham heart study. N Engl J Med 1990; 322:1561-1566.

15. Leite-Moreira AF, Correia-Pinto J and Gillebert TC. Afterload induced changes in myocardial relaxation: A mechanism for diastolic dysfunction Cardiovascular Research 1999; 43: 344-353.

16. Kahan $T$ and Bergfeldt $L$. Left ventricular hypertrophy in hypertension: its arrhythmogenic potential. Heart 2005; 91(2): 250-256.

17. Kumar: Robbins and Cotran Pathologic Basis of Disease, Professional Edition, 8th ed. 2009; chapter 11.

Authors Contribution:

VKN - designed the study, collected the data, analysed the data, drafted \& reviewed the manuscript; NM - drafted \& reviewed the manuscript RS - guided the study.

Source of Support: Nil, Conflict of Interest: None declared. 